Tropical Journal of Pharmaceutical Research December 2012; 11 (6): 947-954

(C) Pharmacotherapy Group, Faculty of Pharmacy, University of Benin

Benin City, 300001 Nigeria.

All rights reserved.

\title{
Effect of Magnesium Administration on Passive Avoidance Memory and Formalin-Induced Nociception in Diabetic Rats
}

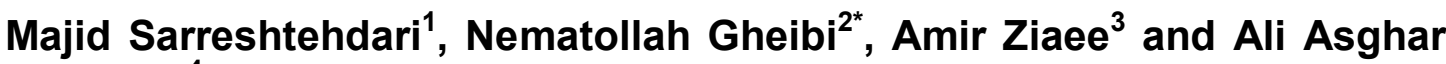 \\ Pahlevan ${ }^{4}$ \\ ${ }^{1}$ Department of Internal Medicine, ${ }^{2}$ Cellular and Molecular Research Center, School of Medicine, ${ }^{3}$ Qazvin Metabolic \\ Disease Research Center, ${ }^{4}$ Cellular and Molecular Research Center and Department of Microbiology, School of \\ Medicine, Qazvin University of Medical Sciences, Qazvin, Iran
}

\begin{abstract}
Purpose: To investigate the effect of oral consumption of magnesium on the memory and pain sensation of diabetic rats.

Methods: A total of 48 rats were divided into four groups - untreated control, untreated diabetic, magnesium-treated control and magnesium-treated diabetic. Plasma magnesium and glucose concentrations were measured after induction of diabetes with streptozotocin (STZ; $60 \mathrm{mg} / \mathrm{kg}$ ). Four weeks after the administration of oral magnesium (10 $\left.\mathrm{g} / \mathrm{L}, \mathrm{MgSO}_{4}\right)$, the animals were subjected to passive avoidance test whereby latency time (LT) was assessed. This was followed by formalin test which entailed the determination of licking and flinching scores

Results: Increased level of glucose and decreased concentration of magnesium in untreated diabetic group compared to untreated control group $(p<0.001)$ were observed. There was also a significant reduction in mean $L T$ of untreated diabetic group $(p<0.001)$ as indicated by the increased number of animals that entered the dark compartment. Plasma glucose and magnesium levels in magnesium treated diabetic rats returned to normal 4 weeks after oral magnesium consumption. There was no significant change in mean total pain score despite elevated licking in diabetic animals after oral magnesium consumption. Significant elevation of flinching scores of untreated diabetic rats was observed in the last 20 min of the 2nd chronic phase, compared with the untreated control group. Conclusion: It seems that magnesium treatment either restores rat memory performance that is impaired by diabetes or that it affects the aversive responses evoked by electrical shock.
\end{abstract}

Keywords: Diabetes, Magnesium, Glucose, Passive avoidance memory, Formalin test. 


\section{INTRODUCTION}

There are several theories regarding the pathology and cognitive impairment in individuals with diabetes [1-2]. The pathways through which the disease affects on cognitive function are abnormality in glucose metabolism and formation of advanced glycation end products [3-4]. Thus, any change in glucose concentrations can affect cognitive function. From a mechanistic standpoint, it is difficult to discern whether the main mechanism relating type II diabetes to cognitive impairment is linked to glycemia, a component of the metabolic syndrome (e.g., hypertension), insulin resistance, or factors specifically related to adipose tissue. The answer could be that there is an aggregate effect of all the components on lifespan [5].

Occurrence of diabetes is a major risk factor for developing senile dementia which is regarded as one of the clinical signs of Alzheimer disease [6]. There are inadequate reports in the literature that associate diabetes and its effects on central nervous system and pain. However, one study has discussed the effect of diabetes on behavior, memory and learning [7]. Pain caused by peripheral nerve neuropathy is also one of the major clinical complaints described by patients with diabetes, and this affects the quality life of those concerned. Thus, alleviation of pain in these patients is of prime importance [8]. The results of a recent study have shown that high blood sugar is main causes of painful neuropathy caused by induced toxicity in peripheral nervous system [9].It seems that magnesium is a factor in the pathogenesis of diabetes as magnesium deficiency has been observed among $25-38$ $\%$ of diabetic patients, in particular among those without an appropriate metabolic control [7]. This element modulates glucose transport across the membranes and is considered an important co-factor in enzymatic systems such as glucose oxidation [10]. The association between diabetes and low magnesium level is well understood and it is known that low magnesium diet leads to impaired insulin secretion and action [11] and that magnesium supplementation has been shown to prevent fructose-induced insulin resistance and lowers the incidence of type II diabetes [12,13]. In addition, the effect of oral consumption of magnesium on glucose control and improving insulin sensitivity is well-documented [14]. There is an inverse correlation between the magnesium absorption and diabetes and hence the diabetic patients are recommended to consume foods rich in magnesium such as cereals and green vegetables [15].

Therefore, the aim of this study was to assess memory performance and pain sensation in diabetic animals following consumption of oral magnesium using passive avoidance memory and formalin tests.

\section{EXPERIMENTAL}

\section{Chemicals}

Magnesium sulfate $\left(\mathrm{MgSO}_{4}\right)$ was provided from Merck Company and used as aqueous solution. Streptozotocin (STZ) was obtained from Sigma in lyophilized form as (1 $\mathrm{g}$ vials).

\section{Animals and treatments}

A total of 48 male rats locally produced in Naval Medical Research Institute (Razi, Co. Iran), weighing 180 - $250 \mathrm{~g}$ were used. The animals were kept in $12 \mathrm{~h}$ light/12 $\mathrm{h}$ dark cycles at $22 \pm 0.5{ }^{\circ} \mathrm{C}$ and freely received water and their normal food. All the experiments were approved by the Ethical Review Committee (Project no. 5167, Qazvin University of Medical Sciences) and were carried out according to the Ethical Guidelines for the Investigations of Experimental Pain in Conscious Animals issued by the International Association for the Pain Study (16).

The animals were divided equally into 4 groups, as follows: normal control, diabetic, magnesium-treated normal, and magnesium- 
treated diabetic $\left(\mathrm{MgSO}_{4}, 10 \mathrm{~g} / \mathrm{L}\right.$ of water). Oral magnesium administration in both magnesium-treated normal and diabetic groups continued for 4 weeks while the other two groups (normal control and diabetic groups) received water only. Induction of diabetes in diabetic groups was accomplished by a single intraperitoneal injection of STZ $(60 \mathrm{mg} / \mathrm{kg})$. One week after STZ injection, the animals with a minimum plasma glucose level of $250 \mathrm{mg} / \mathrm{dl}$ were considered as diabetic. The glucose concentration were measured with enzymatic-calorimetric kit (Zistshimi, Iran).Diabetic rats were given oral magnesium solution $\left(10 \mathrm{~g} / \mathrm{L}, \mathrm{MgSO}_{4}\right)$ in their drinking water for four weeks.

\section{Measurement of plasma magnesium and glucose levels}

Development of diabetes following the administration of STZ was confirmed by measuring the blood glucose and magnesium level using the enzyme-based commercial kits(Zistshimi, Iran).. Plasma glucose and magnesium concentrations were measured spectrophotometrically (Rayleigh UV-2100 Spectrophotometer, China) at 520 and 510 $\mathrm{nm}$ wave lengths, respectively.

\section{Passive-avoidance memory test}

Using a shuttle box, passive-avoidance learning test was applied to measure memory and passive-avoidance response. The learning phase was carried out in four stages after a 5-min adaptation period in the shuttle box. A time interval of $1 \mathrm{~h}$ was considered between the stages of the learning phase, while the waiting time for each animal to enter the dark compartment was $5 \mathrm{~min}$. Animals with LT higher than 5 min were excluded from the study. At the 4th stage of the learning phase and following arrival of the animal into the dark compartment, an electrical current of $1 \mathrm{~mA}$ intensity was applied to the animal footpads. The electrical shock was exerted within the last 5 seconds of the second minute using a shock generator instrument which caused the animal to jump and this was taken as proof of delivery of shock. Shortly after the delivery of shock, the guillotined door was opened to let the shocked animal enter the light compartment followed by removal of the animal from the instrument [17]. The delay time for animals to enter from the light to dark compartments was considered as latency time (LT). Once the 4th stage of learning was completed, data acquisition from the passive-avoidance test as a short-term performance criterion was carried out by determining $\mathrm{LT}$ at different time intervals $(1,6,24$ and $48 \mathrm{~h}$, , and then 1 and 2 weeks) after shock induction. The passiveavoidance learning test was performed following magnesium treatment or induction of diabetes.

\section{Measurement of pain scores (Formalin test)}

Pain assessment was determined by Formalin test. This test was accomplished by injection of $50 \mu \mathrm{l}$ of $2.5 \%$ formalin solution as a chemical noxious stimulus into the animal planar hind paw followed by recording of the associated flinching and licking scores. The test was performed after the final session of passive-avoidance memory test.

\section{Statistical analysis}

Statistical analyses were performed using SPSS (version 16). Differences between the four groups were analyzed using Student ttest and one-way analysis of variance (ANOVA) while multiple comparisons between the groups was carried out with Tukey as post-hoc test. A probability value of $<0.05$ was considered significant.

\section{RESULTS}

\section{Effect of magnesium administration on plasma glucose}

Mean serum glucose data are presented in Figure 1. Plasma glucose level at baseline and after 4 weeks for the untreated control 
group was $107.0 \pm 12.0$ and $124.5 \pm 6.6$ $\mathrm{mg} / \mathrm{dl}$, respectively $(p=0.08)$. Similarly, the glucose concentration of untreated diabetic group at baseline and after 4 weeks was $478.0 \pm 89.0$ and $479.0 \pm 63.0 \mathrm{mg} / \mathrm{dl}$, respectively $(p=0.24)$. In magnesium-treated control group, plasma glucose concentration was $126.6 \pm 18.7 \mathrm{mg} / \mathrm{dl}$ at the beginning of the learning phase and $119.0 \pm 12.5 \mathrm{mg} / \mathrm{dl}$ at the end of 4 weeks $(p=0.13)$. Mean mean plasma glucose level in magnesium-treated diabetic group after 4 weeks was $140.5 \pm$ $24.1 \mathrm{mg} / \mathrm{dl}$ and the difference between this group and the untreated diabetic group was significant $(p<0.001)$. There was no significant difference between the magnesium-treated diabetic and untreated control groups.

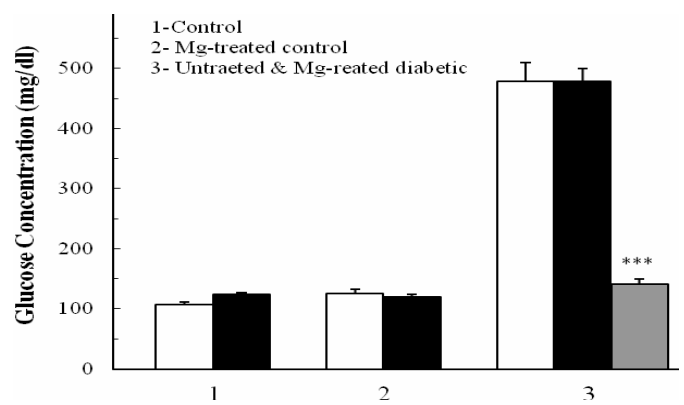

Figure 1: Influence of oral magnesium administration on plasma glucose concentration measured at time zero (transparent bars), after 4 weeks (dark bars), and 4 weeks following magnesium treatment (gray bars) in comparison with untreated diabetic rats; ${ }^{*} p<0.001$.

\section{Effect of magnesium administration on plasma magnesium}

The plasma magnesium level of untreated control was significantly $(p<0.001)$ decreased more than that of the untreated diabetic group $(2.47 \pm 0.18$ versus $1.65 \pm$ $0.15 \mathrm{mg} / \mathrm{dl}$ ). Furthermore, plasma magnesium concentration in magnesiumtreated diabetic group $(2.44 \pm 0.23 \mathrm{mg} / \mathrm{dl})$ significantly increased compared with untreated diabetic group after 4 weeks of magnesium treatment. However, there was no significant difference between the plasma magnesium levels of untreated control, magnesium-treated control, and untreated diabetic groups $(p=0.32)$.

Table 1: Latency time (LT) and frequency of animal entry into the dark compartment in passive avoidance memory test.

\begin{tabular}{lcccc}
\hline $\begin{array}{l}\text { LT after } \\
\text { test }\end{array}$ & $\begin{array}{c}\text { Untreated } \\
\text { Control }\end{array}$ & $\begin{array}{c}\text { Untreated } \\
\text { Diabetic }\end{array}$ & $\begin{array}{c}\text { Magnesiu } \\
\text { m-treated } \\
\text { Control }\end{array}$ & $\begin{array}{c}\text { Magnesiu } \\
\text { m-treated } \\
\text { Diabetic }\end{array}$ \\
\hline $1 \mathrm{~h}$ & $162.0 \pm 2.8$ & $47.7 \pm 1.9^{* * *}$ & - & $147.5 \pm 2.4$ \\
$6 \mathrm{~h}$ & $158.0 \pm 1.8$ & $45.0 \pm 4.9^{* * *}$ & $167.0 \pm 1.4$ & $151.0 \pm 0.9$ \\
$24 \mathrm{~h}$ & $145.0 \pm 0.8$ & $38.0 \pm 5.7^{* * *}$ & $159.0 \pm 1.8$ & $160.0 \pm 2.4$ \\
$48 \mathrm{~h}$ & $135.0 \pm 6.41$ & $41.8 \pm 8.2^{* * *}$ & $152.1 \pm 4.0$ & $152.5 \pm 2.4$ \\
1 week & $122.7 \pm 10.0$ & $35.0 \pm 7.6^{* * *}$ & $151.5 \pm 9.3$ & $120.0 \pm 18.4$ \\
2 week & $112.0 \pm 11.3$ & $36.2 \pm 10.5^{* * *}$ & $133.0 \pm 4.8$ & $91.3 \pm 9.4$ \\
\hline
\end{tabular}

$n=$ number of animals entered the dark compartment of shuttle box (mean $\pm S E M), n=12) ; \quad *=$ Statistical significance $(p<0.001)$ for latency time $(L T)$ values, compared to untreated control group

\section{Effect of magnesium administration on passive avoidance memory}

Evaluation of short-term memory was determined after 1, 6, 24 and $48 \mathrm{~h}$, then 1 and 2 weeks following the 4th phase of learning and application of electrical shock. The results are presented in Table 1. Among the untreated diabetic group, mean LT was significantly lower than that of the untreated control group $(p<0.001)$. In addition, the frequency of entries in untreated diabetic control group was higher than those in untreated control group. Nevertheless, LT for both magnesium-treated control and magnesium-treated diabetic groups was insignificant compared to that of the untreated control.

\section{Effect of magnesium administration on pain}

The results of the evaluation of pain based on the formalin test (licking and flinching pain models) are depicted in Figure 2. The pain score for licking response, both during the acute (first $10 \mathrm{~min}$ ) and chronic phases (15 $60 \mathrm{~min}$ ) for the magnesium-treated diabetic group was significantly $(p<0.05)$ than that for the untreated diabetic animals. 


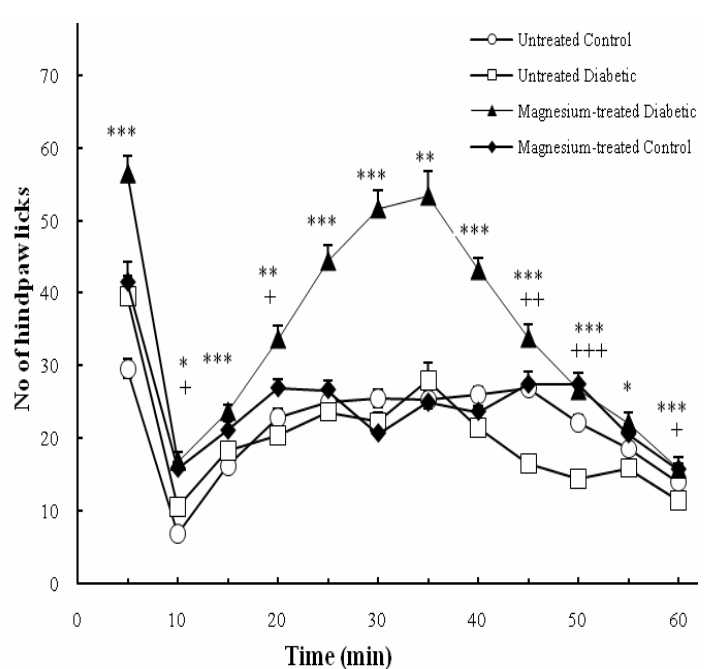

Figure 2: Effect of oral magnesium administration in formalin-induced biphasic pain model (Error bars denote SEM). Key: No. of hindpaw licks in untreated control $(O)$, untreated diabetic $(\diamond)$, magnesium-treated control $(\diamond)$, and magnesiumtreated diabetic $(\boldsymbol{\Lambda})$ groups; * $=$ untreated diabetic in comparison with magnesium-treated diabetic groups; += untreated control in comparison with magnesium-treated control groups. ${ }^{*} p<0.05 ;{ }^{* *} p<$ 0.01 , and ${ }^{* * *} p<0.001$

Magnesium-treated control showed more licking than untreated control in the final 20 min of chronic pain phase (Figure 2).

However, in the flinching response pain model (Figure 3), significantly higher scores were recorded for untreated diabetic and magnesium-treated groups. The flinching scores of untreated diabetic group increased significantly, compared with untreated control group.

The total scores for both acute and chronic phases in magnesium-treated diabetic and magnesium-treated control groups were not significantly different from those of the untreated groups. However, as Figure 4 shows, the total scores for the chronic phase in the magnesium-treated diabetic and untreated diabetic groups were higher than those of magnesium-treated control and untreated control groups.

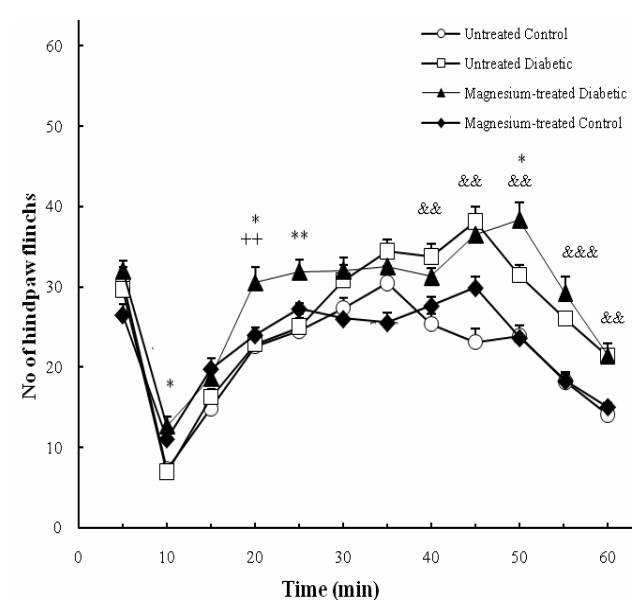

Figure 3: Effect of oral magnesium administration in formalin-induced biphasic pain model (Error bars denote SEM). No. of hindpaw flinches in untreated control $(O)$, untreated diabetic $(\diamond)$, magnesium-treated control $(\diamond)$, and magnesiumtreated diabetic groups $(\boldsymbol{\Delta}) .{ }^{*}=$ untreated diabetic in comparison with magnesium-treated diabetic groups; += untreated control in comparison with magnesium-treated control groups; \&= untreated diabetic in comparison with untreated control groups; ${ }^{*} p<0.05 ;{ }^{* *} p<0.01$, and ${ }^{* * *} p<0.001$

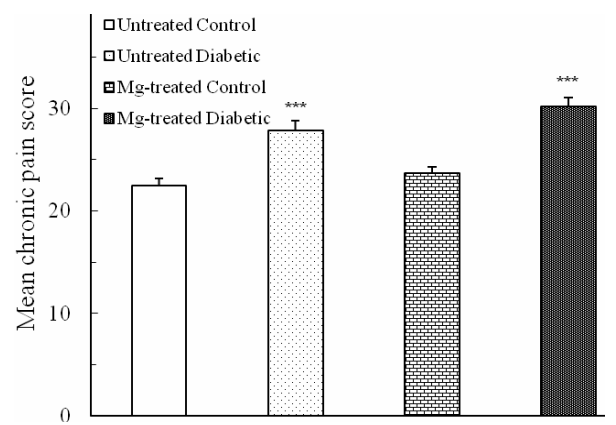

Figure 4: Mean total scores for chronic pain phase in four experimental groups. ${ }^{* \star *} p<0.001$

\section{DISCUSSION}

Since total pain score in chronic pain phase was higher for untreated and magnesiumtreated diabetic groups than for untreated and magnesium-treated control groups, it can be said that the hyperalgesia produced in the two diabetic groups was induced by elevated blood glucose. Furthermore, the aversive 
response in magnesium-treated diabetic group; evoked by electrical shock, returned to its normal range. The higher LT values and the low number of animals entered the dark compartment for the magnesium-treated control group may be attributed to the increased sensitivity to electrical shock, leading to a mild alteration in aversive response. However, this assumption needs further investigation since the pain induced by formalin is due to a chemical noxious stimulus which is different from that induced by an electrical shock.

Magnesium reduction occurs in both type-1 and type-2 diabetes especially when toxins such as streptozotocin with known strong diabetogenic and pathologic effects (e.g., hypertension) are used [18-19]. Furthermore, it has been reported that continuous high serum glucose level is often accompanied by reduced magnesium serum level and that there is a correlation between magnesium deficiency, on the one hand, and insulin resistance and decreased insulin secretion in diabetic patients [20-21]. Many physicians have suggested daily administration of 300 $400 \mathrm{mg}$ of magnesium in diabetic patients having normal kidney function [15]. The restoration of plasma glucose concentration to the same level as that of control indicates that the mechanism is probably to that through which glucose transfer within membranes is modulated by magnesium and is considered an important cofactor in enzymatic systems such as glucose oxidation [14].

The present study revealed differences between the animal groups with regard to memory processing and function. Decrease in the latency time (LT) of the diabetic animals as well as the increase in the number of animals that entered the dark compartment are indicative of poor cognitive function induced by diabetes; this is consistent with earlier findings [1-2]. This is buttressed by entry of animals into the dark compartment 2 weeks later, indicating disappearance of memory associated with electrical shock.
After four weeks of magnesium treatment, there was a significant decrease in the plasma glucose concentration and improvement in cognitive performance of the animals with experimentally-induced diabetes.

As reported by Obrosova, peripheral neuropathy is the most important and generalized complications of diabetic patients with a frequency of up to $60 \%$ [22]. Neuropathic pain is a chronic pain manifested by a change in pain nociception, accelerated feeling of pain in response to painful stimuli (hyperalgesia), and abnormal painful sensitivity to those stimuli that were not painful earlier (allodynia) [23]. In an acute thermal test for pain processing, which involved measurement of pain threshold through tail flick latency, it was shown that oral magnesium administration prevents thermal hyperalgesia induced by diabetes in rats [24]. In agreement with our study, the findings of a recent report showed a significant reduction in plasma magnesium levels in diabetic animals. However, this condition was restored by 8-week oral magnesium administration, correcting the thermal pain threshold and plasma glucose level [24].

Formalin-induced pain behavior is considered a valid model of clinical pain (i.e., chronic pain experienced by man). The period of pain-induced behavior following subcutaneous injection of dilute formalin into rat hindpaw is divided into two phases, namely, an acute phase which is a temporary provocative response lasting approximately 2 - 5 min and a chronic phase which continues for at least 25 - $40 \mathrm{~min}$, depending on the concentration of formalin used [25]. In the present study, the biphasic model of pain was clearly differentiated and recognized through licking and flinching modalities of pain. In this pain model, diabetic animals with no magnesium consumption showed an aggravated pain on both scores compared to control group, indicating the effects of neuropathy and hyperglycemia. In addition, 
both diabetic and normal groups treated with magnesium for 4 weeks showeded hyperalgesia, unlike groups without magnesium treatment. It seems that the higher magnesium dose used in these animals is the likely cause of the hyperalgesia. It has been reported that an inverse correlation between magnesium absorption and diabetes exists, which is why diabetic patients are advised to consume foodstuffs rich in magnesium, such as cereals and green vegetables [15].

\section{CONCLUSION}

Based on the findings of the present study, it is clear that while oral administration of magnesium causes a significant decrease in plasma glucose, it considerably increases plasma magnesium levels in diabetic animals. Furthermore, long-term consumption of magnesium leads to the increased ability of diabetic animals to store information in memory space as well as increase their capacity to recall stored information.

\section{ACKNOWLEDGEMENT}

The authors would like to appreciate the Deputy of Research Department of Qazvin University of Medical Sciences for his valuable assistance. We also thank colleagues who rendered various forms of assistance in the course of this study.

\section{REFERENCES}

1. Kumari $M$, Brunner $E$, Fuhrer $R$. Mini review: mechanisms by which the metabolic syndrome and diabetes impair memory. $J$ Gerontol A Biol Sci Med Sci 2000; 55: B228-B232.

2. Biessels GJ. Cerebral complications of diabetes: clinical findings and pathogenetic mechanisms. Neth J Med 1999; 54: 35-45.

3. Stolk RP, Breteler MMB, Ott A, Pols HAP, Lamberts SWJ, Grobbee DE, Hofman A. Insulin and cognitive function in an elderly population: The Rotterdam Study. Diabetes Care 1997; 20: 792-795.

4. Craft S, Peskind E, Schwartz MW, Schellenberg GD, Raskind M, Porte DJ. Cerebrospinal fluid and plasma insulin levels in Alzheimer's disease: relationship to severity of dementia and apolipoprotein E genotype. Neurology 1998; 50: 164-168.

5. Luchsinger JA. Type 2 diabetes and cognitive impairment: linking mechanisms. J Alzheimers Dis. 2012; 30(0): S185-S198

6. Jackson-Guilford J, Leander JD, Nisenbaum LK. The effect of streptozotocin-induced diabetes on cell proliferation in the rat dentate gyrus. Neurosci Letter 2000; 293: 91-94.

7. Biessels GJ, Smale S, Duis SE, Kamal A, Gispen WH. The effect of gamma-linolenic acid-alpha lipoic acid on functional deficits in the peripheral and central nervous system of streptozotocin diabetic rats. J Neurol Sci 2001; 182: 99-106.

8. Dobretsov M, Hastings SL, Romanovsky D, Stimers $J R$, Zhang JM. Mechanical hyperagesia in rat models of systemic and local hyperglycemia. Brain Res 2003; 960: 167-176.

9. Dobretsov M, Hastings SL, Stimers JR, Zhang JM. Mechanical hyperagesia in rats with chronic perfusion of lumbar dorsal root ganglion with hyperglycemic solution. J Neurosci Methods 2001; 110: 9-15

10. de Lordes Lima M, Cruz T, Pousada JC, Rodrigues LE, Barbosa K, Canguçu V. The effect of Magnesium Supplementation in Increasing Doses on the Control of Type 2 diabetes. Diabetes care 1998; 21(5): 682-686.

11. Suarez A, Pulido N, Casla A, Casanova B, Arrieta FJ, Rovira A. Impaired tyrosine-kinase activity of muscle insulin receptors from hypomagnesaemic rats. Diabetologia 1995; 38: 1262-1270.

12. Balon TW, Gu JL, Tokuyama Y, Jasman AP, Nadler JL. Magnesium supplementation reduces development of diabetes in a rat model of spontaneous NIDDM. Am J Physiol 1995; 269 (4-1): E745-E752.

13. Balon TW, Jasman A, Scott S, Meehan WP, Rude RK, Nadler JL. Dietary magnesium prevents fructose-induced insulin insensitivity in rats. Hypertension 1994; 23 (6 Pt 2): 1036-1039.

14. De Valk HW. Magnesium in diabetes mellitus. Neth J Med 1991; 54: 139-146.

15. Lopez-Ridaura R, Willett WC, Rimm EB, Liu S, Stampfer MJ, Manson JE, Hu FB. Magnesium intake and risk of type 2 diabetes in men and women. Altern Med Rev 2006; 11(4): 294-329.

16. Zimmermann, M. 1983. Ethical guidelines for investigations of experimental pain in conscious animals. Pain 1983; 16: 109-110.

17. Motamedi F, Ghasemi M., Ghiafeh Davoodi F, Naghdi N. Comparison of learning and memory in morphine dependent rats using different behavioral models. Iranian $J$ Pharmaceut Res 2003; 2(4): 225-230.

18. Mather $H$, Nisbet JA, Burton GH, Poston GJ, Bland JM, Bailey PA, Pilkinaton TRE. Hypomagnesaemia in diabetes. Clin Chim Acta 1997; 95: 235-242.

19. Barbagallo M, Resnick LM, Dominguez LJ, Licata G. Diabetes mellitus, hypertension and ageing: 


\section{Sarreshtehdari et al}

the ionic hypothesis of ageing and cardiovascular-metabolic diseases. Diabetes Metab 1997; 23: 281-294.

20. Ma J, Folsom AR, Melnick SL, Eckfeldt JH, Sharrett $A R$, Nabulsi AA, Hutchinson RG, Metcalf $P A$. Associations of serum and dietary magnesium with cardiovascular disease, hypertension, diabetes, insulin, and carotid arterial wall thickness: the ARIC study. Atherosclerosis risk in communities study. J Clin Epidemiol 1995; 48: $927-940$

21. Yokota K. Diabetes mellitus and magnesium. Clin Calcium 2005; 15(2): 203-212.

22. Obrosova IG. Update on the pathogenesis of diabetic neuropathy. Curr Diab Reports 2003; 3(6): 439-445.
23. Sounvoravong $S$, Nakashima $M N$, Wada $M$, Nakashima K. Decrease in serotonin concentration in raphe magnus nucleus and attenuation of morphine analgesia in two mice models of neuropathic pain. Eur J Pharmacol 2004; 484(2-3): 217-223.

24. Hasanein $P$, Parviz $M$, Keshavarz $M$, Javanmardi $K$, Mansoori $M$, Soltani $N$. Oral magnesium administration prevents thermal hyperagesia induced by diabetes in rats. Diabetes Res Clin Pract 2006; 73: 17-22.

25. Tjolsen A, Berge OG, Hunskaar S, Rosland JH, Hole $K$. Formalin test: an evaluation of the method. Pain 1992; 51: 5-17. 